to see that the albumin was steadily increasing in quantity. On August 26 th it had risen to a fifth, 57 ounces being passed during the 24 hours. The specific gravity was still 1012. On Sept. 11th the albumin had again risen and now stood at a third, while the specific gravity had dropped to 1007, more urine (60 ounces) being passed in the 24 hours. Irritability of the bladder then occurred and continued in spite of large doses of hyoscyamus and buchu, and it became evident that the urotropin itself, clarifying in character as it had been to the contents of the bladder, was accountable for this by virtue of one of the products, formaldehyde, into which the urotropin had become decomposed. The urotropin was at once omitted and not only was there complete cessation of vesical irritation, but in 24 hours' time the albumin, instead of being one-third of the volume of the urine-the maximum which it reached-had become reduced to a mere trace as on August 3rd. This result appears to show that urotropin, if given for a sufficient time, may not only cause persistent vesical irritability even with an acid, normal-smelling, nonsedimentary urine, but in certain circumstances it may produce a nephritic irritation of a decidedly detrimental character.

The chemistry of this hydrolytic decomposition of urotropin into formaldehyde and an ammonium salt is easily demonstrable by a simple laboratory experiment. The interesting feature is that it can only take place in an acid medium. If an aqueous solution of urotropin be boiled with a little liquor potassæ no decomposition occurs, but if dilute sulphuric acid be substituted for the liquor potassæ and the liquid gently warmed formaldehyde, which is easily recognised by its penetrating odour, is generated. If the formaldehyde be completely eliminated by boiling and the acid liquid rendered alkaline with liquor potassæ and warmed, ammonia, the other product of the hydrolytic degradation of urotropin, is evolved and easily identified. In other words, urotropin, hexamethylenetetramine, $\mathrm{C}_{6} \mathrm{H}_{12} \mathrm{~N}_{4}$, is hydrolysed, under certain conditions, into the two substances from which it was originally derived. Equations 1 and 2 represent its formation and hydrolytic decomposition respectively :-

(1) $6 \mathrm{CH}_{2} \mathrm{O}+4 \mathrm{NH}_{3}=\mathrm{C}_{6} \mathrm{H}_{12} \mathrm{~N}_{+}+6 \mathrm{H}_{2} \mathrm{O}$

(2) $\mathrm{C}_{6} \mathrm{H}_{12} \mathrm{~N}_{4}+6 \mathrm{H}_{2} \mathrm{O}=6 \mathrm{OH}_{2} \mathrm{O}+4 \mathrm{NH}_{3}$.

As a rule, this process of splitting up urotropin into formaldehyde and ammonia presumably takes place in the bladder in an acid urine but from the observations made in this case it would appear in some circumstances to take place in the kidney or in the blood before it reaches this organ. This hypothesis, however, unfortunately involves an apparent inconsistency-namely, that the blood is not an acid medium-so that there is a temptation to conclude that at these times this hydrolytic process must take place in the kidney itself.

Crouch End-hill, N.

\section{A CASE OF A SHARP FOREIGN BODY SWALLOWED AND SUBSEQUENTLY PASSED IN THE NATURAL MANNER.}

By R. A. Belrlios, M.D. Edin., F.R.C.S. Edin.

Is connexion with the article entitled "A Case of Perforation of the Duodenum by a Bodkin; Laparotomy; Recovery," I the following notes of a case observed in my practice recently may be of interest.

The foreign body was a steel pin two inches in length, needle-pointed, with a small black glass knob. On the evening of June 2lst last the patient, a woman, disturbed in some manner in the act of putting on a hat and having the pin between her lips, by a sudden inhalation drew the object to the back of her throat, whence it was instantly swallowed. On laryngoscopic examination no abrasion, \&c., could be detected and for a time no discomfort was complained of. The patient was at once put on a diet of porridge and instructed to take a quantity of small pieces of uncoloured Berlin wool, at the same time rest being enjoined and a watch kept for symptoms. Purgatives and any excessive quantity of fluids were absolutely interdicted. It must be confessed that little of the wool was used by the patient but a considerable quantity of the oatmeal was taken for a few meals. Up to the morning of the 24th (two and a half days after the accident) there were no symptoms and then the patient began to complain of some vague gnawing pains in the hypogastric region. About six or eight hours after their onset she passed by the bowel some pieces of casts, five-eighths of an inch in diameter, which on microscopic examination were found to consist chiefly of mucus together with some changed blood. The fragments were about six inches in length. It was not possible to ascertain their exact number but probably about half a dozen were passed up to the morning of the $26 \mathrm{th}$. The same evening (the 24th) the patient complained of pains, sharp and pricking in character, and localised to the region of the appendix. An examination, which for obvious reasons was very gently made, revealed, with the exception of slight tenderness in that particular region, nothing abnormal. T'he temperature, pulse, and general condition were quite correct throughout and there was never any reason for suspecting the onset of any inflammatory change. The pains in the lower regions of the abdomen continued and although never urgent were most marked through the night of the 25th. On the morning of the $26 \mathrm{th}$, and to the great relief of the patient, the pin was passed in safety exactly four and a balf days after the accident.

The points to which I would call attention in this particular case are: (1) the passage of the mucous casts, due presumably to certain changes in the glandular activity of the intestines owing to irritation of the foreign body whereby the casts were formed and passed; and (2) the fact that purgatives and much fluid were absolutely forbidden and that instead a diet was prescribed which to my mind was calculated to travel with, and to some extent to form a sort of protective coating to, the needle-pointed foreign body in its course through the various curves of the intestinal canal.

Muswell-hill, N.

\section{A CASE OF CLAY-COLOURED STOOLS WITHOUT JAUNDICE BUT ATTENDED WITH COPIOUS BILIOUS VOMIT.}

By W. Gordon, M.D. Cantrab., F.R.C.P. Lond, PHYSICIAN TO THE DEYON AND EXETER HOSPITAT.

IN 1889 the late Sir Andrew Clark communicated to the Royal Medical and Chirurgical Society for Dr. T. J. Walker a paper on the Significance of "Colourless" Stools without Jaundice, in which Dr. Walker described two cases of obstruction of the pancreatic duct where the stools were clay coloured, although the liver, bile-duct, and bile were found post mortem to be normal. Dr. Walker drew the conclusion that the formation of the colouring matter of the freces depended on the mutual reaction of the bile and pancreatic fluid under the influences met with in the intestinal tract. He quoted Claude Bernard, who in 1856 wrote with reference to dogs whose pancreas had been destroyed : "It is remarkable that bile only colours the fæces a very bright yellow, whilst with the pancreatic juice the bile takes a very brown colour. The pancreatic juice therefore contributes indirectly to the colouring of the fæces." The conclusions of Dr. Walker have received less attention than might have fairly been expected. In his two cases, also, it will be observed that the presence of sufficient bile entering the bowel to colour the freces was a matter of inference. On both these accounts, therefore, the following case, which I observed with Dr. C. J. Vlieland, should be of interest, not merely as supporting Dr. Walker's conclusion, but as demonstrating during life that an abundance of bile may enter the duodenum, yet, if the pancreatic juice is cut off from the intestine, stercobilin may be absent from the fæces.

Our patient was a middle-aged labouring man suffering from intense pain in the upper part of the abdomen, copious vomiting of green bile, and the passage of clay-coloured or, occasionally, pale cream-coloured motions. We diagnosed cancer of the pancreas, basing our opinion partly on Dr. Walker's observations. The vomit was of the ordinary olivegreen colour produced by biliverdin and a large quantity of it was ejected. The motions were soft but formed, sometimes clay-coloured, as in cases of complete obstruction of the bile duct, sometimes faintly cream-coloured or primrosecoloured. They were never brown. At the necropsy Dr. Vlieland found a cancer involving the head of the pancreas and obliterating the pancreatic duct.

With regard to the colour of the motions, Mr. A. W. Mayo 